\title{
Critical Success Factors of Knowledge Management System in Vietnam
}

\author{
Tran Hoai Nam \\ Department of E-commerce, Vietnam University of Commerce, Hanoi, Vietnam
}

Email address:

namdhtm@gmail.com

\section{To cite this article:}

Tran Hoai Nam. Critical Success Factors of Knowledge Management System in Vietnam. International Journal of Business and Economics Research. Vol. 4, No. 6, 2015, pp. 323-327. doi: 10.11648/j.ijber.20150406.18

\begin{abstract}
Knowledge management plays a very important role in business operation, especially in the efficient exploitation of information or knowledge resources through technology. Technology provides the basic tools for implementing and improving the efficiency of knowledge management activities within an enterprise. To understand the relative influence of various factors in improving knowledge management systems, this study used data from 92 Vietnamese enterprises having knowledge management systems. The study identified a number of important factors directly affecting the success of knowledge management system in Vietnam enterprises. Based on the results of this study, the authors gave several recommendations for Vietnam enterprises in the development and application of knowledge management systems, and suggested future studies.
\end{abstract}

Keywords: Knowledge Management System, Critical Success Factors, Technology, Vietnam

\section{Introduction}

Knowledge management system (KMS) is defined by Alavi and Leidner (2001, p114) as "Information Technology (IT)-based systems developed to support and enhance the organizational processes of knowledge creation, storage/retrieval, transfer, and application". Maier (2002) expanded on the IT concept for the KMS by naming it an ICT (Information and Communication Technology) system that supported the functions of knowledge creation, construction, identification, capturing, acquisition, selection, valuation, organization, linking, structuring, formalization, visualization, distribution, retention, maintenance, refinement, evolution, accessing, search, and application.

A successful KMS should implement effectively the function of knowledge creation, storage, recovery, transfer and application. However, the success of this system depends on many factors. To make KMS work productively, leaders need to figure out in detail the factors that play a decisive role for the success of this particular system. There have been many previous studies in the world relating to this issue. However in Vietnam, the field of knowledge management and its system in the enterprise has not been implemented researching (Nam, 2014). Therefore, this study aims to research on the critical success factors for KMS in Vietnam enterprises.

\section{Literature Review and Hypothesis Development}

Knowledge Management System is socio-technical system which has many technical-economic-social factors impacting on the success of knowledge management of the enterprise.

Mandevilla, Eulgem, Mould and Rao (1998) has studied and described some elements of technology and strategy that influence the design of a KMS include: the focus of the KMS (who are the users), what formats the quantity of knowledge are kept, how to exploit and the use of individual memories.

Jennex and Olfman (2000) studied three KM projects to identify recommendations for building a successful KMS. Some of the key recommendations include:

- Developing the good technical infrastructure by using a common network structure, adding skills in knowledge management technology, using a personal computer, database integration and standardizing hardware and software throughout the organization.

- Combination of KMS in the daily process by using auto-save system knowledge.

- Having a knowledge structure for business.

- Having support from senior management to knowledge management. 
- Creating and implementing a knowledge management strategy or plan to determine and maintain knowledge base.

- Expanding system models/life cycles to include the KMS and assess system/process changes for impact on the KMS.

- Designing security into the KMS.

- Building motivation and commitment by combining the use of KMS in the process of evaluating employees, implementing KMS use/ satisfaction metrics, identifying organizational culture concerns that may affect KMS usage.

Mahotra and Galletta (2003) surveyed users of KM system being implemented in a health care organization and identified the importance of user motivation and commitment.

Ginsberg and Kambil (1999) explore the issues in designing and implementing an effective KMS by building a KMS based on the issues identified in the document and then testing KMS implementation. They found knowledge representation, storage, search, retrieval, visualization, and quality control to be key technical issues, and incentives to share and use knowledge to be the key organizational issues.

Alavi and Leidner (1999) surveyed executive managers of KM system. Results showed that organizational and cultural issues accompanied with user motivation to share and use knowledge had the most importance in success of KM system. Besides, measuring KM system benefits and having integrated technical architecture that support databases, communications and search and retrieval operations were crucial.

Holsapple and Joshi (2000) surveyed 31 experts and researchers in KM through the use of Delphi technique and extracted critical factors that influence the management of knowledge in organization. These factors include leadership and commitment of top management, financial support, skill level of employees and known knowledge sources in organization.

Davenport and Prusak (1998) investigated tacit knowledge as a promoter of success in technology firms by studying ten small technology firms. Key to the success of a KMS was the ability to identify, capture, and transfer critical tacit knowledge. A significant finding was that new members take a long time to learn critical tacit knowledge and a good KMS facilitates the transference of this tacit knowledge to new members.

Barna (2003) studied six KM projects and identified two groups of factors important to a successful KMS. The main managerial success factor is creating and promoting a culture of knowledge sharing within the organization by articulating a corporate $\mathrm{KM}$ vision, rewarding employees for knowledge sharing, creating communities of practice, and creating a "best practices" repository. Other managerial success factors include obtaining senior management support, creating a learning organization, providing KMS training, and precisely defining KMS project objectives. Design/construction success factors include approaching the problem as an organizational problem and not a technical one; creating a standard knowledge submission process; having methodologies and processes for the codification, documentation, and storage of knowledge; having processes for capturing and converting individual tacit knowledge into organizational knowledge; and creating relevant and easily accessible knowledge-sharing databases and knowledge maps.

Cross and Baird (2000) proposes that KM would not improve business performance simply by using technology to capture and share the lessons of experience. It was postulated that for $\mathrm{KM}$ to improve business performance it had to increase organizational learning through the creation of organizational memory. To investigate this proposition, 22 projects were examined. The conclusion was that improving organizational learning increased the likelihood of $\mathrm{KM}$ success. Factors that improved organizational learning include:

- Supporting personal relationships between experts and knowledge users.

- Providing incentives to motivate users to learn from experience and to use the KMS.

- Providing distributed databases to store knowledge and pointers to knowledge.

- Providing work processes for users to convert personal experience into organizational learning.

- Providing direction to what knowledge the organization needs to capture to produce learning.

Sage and Rouse (1999) reflected on the history of innovation and technology and identified the following issues:

- Modeling processes to identify knowledge needs and sources.

- KMS strategy for the identification of knowledge to capture and use and who will use it.

- Provide incentives and motivation to use the KMS.

- Infrastructure for capturing, searching, retrieving, and displaying knowledge.

- An understood enterprise knowledge structure.

- Clear goals for the KMS.

- Measuring and evaluating the effectiveness of the KMS. $\mathrm{Yu}$, Kim, and Kim (2004) explored the linkage of organizational culture to knowledge management success. They found that KM drivers such as a learning culture, knowledgesharing intention, KMS quality, rewards, and KM team activities significantly affected KM performance. These conclusions were reached through a survey of 66 Korean firms.

Table 1. Summary of critical success factors for KMS.

\begin{tabular}{lll}
\hline STT & Success Factor & Sources \\
\hline \multirow{2}{*}{$\begin{array}{l}\text { Awareness the role of knowledge management and } \\
\text { the use of KMS }\end{array}$} & $\begin{array}{l}\text { Barna (2002), Davenport et al. (1998), Holsapple and Joshi (2000), Jennex and Olfman } \\
\text { (2000), Yu et al. (2004) }\end{array}$ \\
& $\begin{array}{l}\text { Enterprises have clear strategies and objectives for } \\
\text { the use of KMS }\end{array}$ & $\begin{array}{l}\text { (2002), Ginsberg and Kambil (1999), Holsapple and Joshi (2000), Jennex et al. } \\
\text { Baird (2000), Davenport et al. (1998) }\end{array}$ \\
\hline
\end{tabular}




\begin{tabular}{|c|c|c|}
\hline STT & Success Factor & Sources \\
\hline 3 & $\begin{array}{l}\text { The communication and interaction tools (including } \\
\text { intranet, website, email, telephone, Internal } \\
\text { newsletter, portal, chat, social network...) }\end{array}$ & $\begin{array}{l}\text { Alavi and Leidner (1999), Barna (2002), Cross and Baird (2000), Davenport et al. } \\
\text { (1998), Ginsberg and Kambil (1999), Jennex and Olfman (2000), Mandviwalla et al. } \\
\text { (1998), Sage and Rouse (1999), Yu et al. (2004) }\end{array}$ \\
\hline 4 & $\begin{array}{l}\text { The e-learning and business support technologies } \\
\text { (including e-learning system, database management, } \\
\text { document, operational systems and support decision- } \\
\text { making, internal portals and automatic data } \\
\text { collection... }\end{array}$ & $\begin{array}{l}\text { Alavi and Leidner (1999), Barna (2002), Cross and Baird (2000), Davenport et al. } \\
\text { (1998), Ginsberg and Kambil (1999), Jennex and Olfman (2000), Mandviwalla et al. } \\
\text { (1998), Sage and Rouse (1999), Yu et al. (2004) }\end{array}$ \\
\hline 5 & $\begin{array}{l}\text { Motivation and Commitment of users including } \\
\text { incentives and training }\end{array}$ & $\begin{array}{l}\text { Alavi and Leidner (1999), Barna (2002), Cross and Baird (2000), Davenport et al. } \\
\text { (1998), Ginsberg and Kambil (1999), Jennex and Olfman (2000), Malhotra and Galletta } \\
\text { (2003), Yu et al. (2004) }\end{array}$ \\
\hline 6 & $\begin{array}{l}\text { An organizational culture that supports learning and } \\
\text { the sharing and use of knowledge }\end{array}$ & $\begin{array}{l}\text { Barna (2002), Cross and Baird (2000), Alavi and Leidner (1999), Davenport et al. } \\
\text { (1998), Jennex and Olfman (2000), Sage and Rouse (1999), Yu et al. (2004) }\end{array}$ \\
\hline 7 & $\begin{array}{l}\text { The role of KMS for enterprises (help improve } \\
\text { efficiency in searching, sorting, grading, storing } \\
\text { knowledge and managing knowledge of the } \\
\text { enterprise) }\end{array}$ & $\begin{array}{l}\text { Barna (2002), Cross and Baird (2000), Jennex and Olfman (2000), Alavi and Leidner } \\
\text { (1999), Davenport et al. (1998), Jennex and Olfman (2000), Sage and Rouse (1999) }\end{array}$ \\
\hline 8 & Stability and effectiveness of KMS & $\begin{array}{l}\text { Barna (2002), Cross and Baird (2000), Jennex and Olfman (2000), Alavi and Leidner } \\
\text { (1999), Jennex and Olfman (2000), Sage and Rouse (1999) }\end{array}$ \\
\hline
\end{tabular}

Source: author.

As these factors are summarized above, the authors propose a reseach model of the success factors of the knowledge management system including 8 hypotheses about the success factors of KMS in the enterprise:

- Hypothesis 1 (H1): Awareness the role of knowledge management and the use of KMS influences positively to the success of KMS.

- Hypothesis 2 (H2): Enterprises have clear strategies and objectives for the use of KMS that influences positively to the success of KMS.

- Hypothesis 3 (H3): The communication and interaction tools affect positively to the success of KMS.

- Hypothesis 4 (H4): The e-learning and business support technologies affect positively to the success of KMS.

- Hypothesis 5 (H5): Motivation and commitment of employees affect positively to the success of KMS.

- Hypothesis 6 (H6): Cultural organizations (conformity to create learning environments and encourage sharing, acquisition and use of knowledge) impact positively to the success of KMS.

- Hypothesis 7 (H7): The role of KMS for business activity affect positively to the success of KMS.

- Hypothesis 8 (H8): Degree of stability and effectiveness of KMS influence positively to the success of KMS.

These assumptions are described in Figure 1.

\section{Research Methodology}

\subsection{Data Collection}

Data was collected from August 2015 to October 2015 via online survey system named Survey Monkey at: https://www.surveymonkey.com/r/V93DTS8.

Respondents are representatives of businesses who have deployed knowledge management systems in businesses, mainly on two city area, Hanoi and HCMC.

A total of 92 complete responses, valid to be used for the analysis. The basic statistical survey data are reflected in Table 2.

Table 2. Characteristics of the survey data $(N=92)$.

\begin{tabular}{|c|c|c|}
\hline Data Features & Numbers & Rate (\%) \\
\hline \multicolumn{3}{|l|}{ - Business distribution } \\
\hline Ha Noi & 73 & 79.3 \\
\hline Ho Chi Minh city & 18 & 19.6 \\
\hline Others & 1 & 1.1 \\
\hline \multicolumn{3}{|l|}{ - Operating time } \\
\hline Under 3 years & 19 & 20.7 \\
\hline From 3-5 years & 10 & 10.9 \\
\hline From 5-10 years & 29 & 31.5 \\
\hline Over 10 years & 34 & 37.0 \\
\hline \multicolumn{3}{|l|}{ - Types of business structures } \\
\hline Government-owned corporation & 11 & 12.0 \\
\hline Joint stock company & 37 & 40.2 \\
\hline Limited Liability Company & 23 & 25.0 \\
\hline Others & 21 & 22.8 \\
\hline \multicolumn{3}{|l|}{ - Business Scope } \\
\hline Produce & 27 & 29.3 \\
\hline Commerce & 19 & 50.0 \\
\hline The service & 46 & 20.7 \\
\hline (ICT sector) & 20 & 21.7 \\
\hline \multicolumn{3}{|l|}{ - Number of employees } \\
\hline Less than 50 & 49 & 53.3 \\
\hline From 51-100 & 20 & 21.7 \\
\hline From $101-300$ & 4 & 4.3 \\
\hline Over 300 & 19 & 20.7 \\
\hline \multicolumn{3}{|l|}{ - Capital (VNĐ) } \\
\hline Less than 500 million & 9 & 9.8 \\
\hline From 500 million - 1 billion & 15 & 16.3 \\
\hline From 1 billion - 5 billion & 23 & 25.0 \\
\hline From 5 billion - 10 billion & 8 & 8.7 \\
\hline Over 10 billion & 37 & 40.2 \\
\hline \multicolumn{3}{|l|}{ - Revenue (VNĐ) } \\
\hline Less than 1 billion & 19 & 20.7 \\
\hline From 1 billion - 10 billion & 30 & 32.6 \\
\hline From 10 billion - 50 billion & 17 & 18.5 \\
\hline From 50 billion - 100 billion & 8 & 8.7 \\
\hline Over 100 billion & 18 & 19.6 \\
\hline
\end{tabular}

Source: author. 


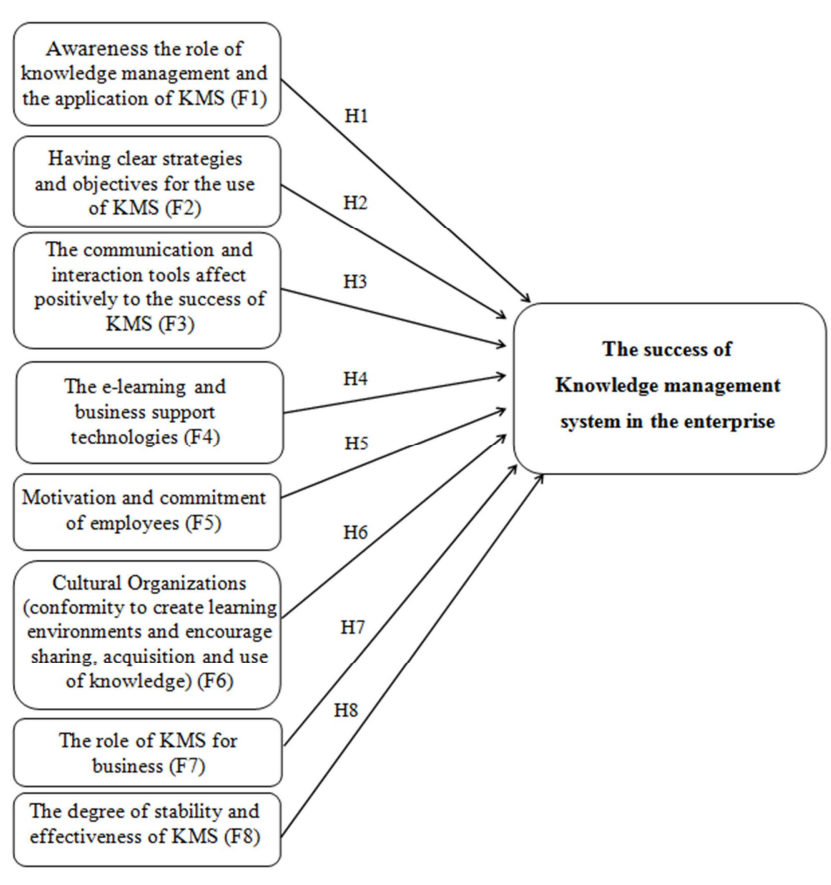

Figure 1. Research Model.

\subsection{Measurement}

The questionnaire was designed to measure factors by the multiple structures based on synthesis of many previous researches about knowledge management system and application of knowledge management system within the organization which have high reliability. We use Likert scale with five points: (1) The lowest level (do not agree); (5) The highest level (strongly agree). The author has used the program SPSS statistical analysis to analyze all data for the purposes of research. This study mainly uses reliability analysis and linear regression analysis to test the hypotheses.

\section{Results and Discussion}

\subsection{Analysis Results}

After using the data analysis to examine the value and the reliability of the scale, researcher analyzed the linear regression. Results of analysis shows in Table 3 and Table 4.

Table 3 show results of linear regression analysis. Adjusted $\mathrm{R}$ Square of $61.7 \%$ indicates that all independent variable jointly explain $61.7 \%$ of variance of the model.

As the results, the factors affecting the success of KMS are: F1 (Awareness the role of knowledge management and the application of KMS), F5 (Motivation and commitment of employees), F6 (Culture organizations) and F8 (Stability and effectiveness of KMS) at the significant level of $5 \%$.

Table 3. Model Summary.

\begin{tabular}{llllllllll}
\hline \multicolumn{7}{c}{ Change Statistics } \\
\hline Model & R & R Square & Adjusted R Square Std. Error of the Estimate & R Square Change & F Change & df1 & df2 & Sig. F Change \\
\hline 1 & $.807 \mathrm{a}$ & .651 & .617 & .59952 & .651 & 19.322 & 8 & 83 & .000 \\
\hline
\end{tabular}

a. Predictors: (Constant), F1, F2, F3, F4, F5, F6, F7, F8.

Table 4. Results of regression analysis.

\begin{tabular}{|c|c|c|c|c|c|c|}
\hline \multirow{2}{*}{\multicolumn{2}{|c|}{ Model }} & \multicolumn{2}{|c|}{ Unstandardized Coefficients } & \multirow{2}{*}{$\begin{array}{l}\text { Standardized Coefficients } \\
\text { Beta }\end{array}$} & \multirow{2}{*}{$-\mathbf{t}$} & \multirow{2}{*}{ Sig. } \\
\hline & & B & Std. Error & & & \\
\hline \multirow{9}{*}{1} & (Constant) & .231 & .405 & & .570 & .570 \\
\hline & $\underline{\mathrm{F} 1}$ & .228 & .071 & .248 & 3.185 & .002 \\
\hline & $\mathrm{F} 2$ & -.059 & .120 & -.057 & -.494 & .623 \\
\hline & F3 & -.076 & .081 & -.071 & -.938 & .351 \\
\hline & F4 & -.042 & .068 & -.042 & -.624 & .534 \\
\hline & $\underline{\text { F5 }}$ & .301 & .145 & .292 & 2.074 & .041 \\
\hline & $\underline{\mathrm{F} 6}$ & .308 & .154 & .290 & 1.999 & .049 \\
\hline & F7 & -.022 & .083 & -.023 & -.268 & .789 \\
\hline & $\underline{\mathrm{F} 8}$ & .324 & .090 & .277 & 3.594 & .001 \\
\hline
\end{tabular}

a. Dependent Variable: Y.

\subsection{Discussions}

Basically, the paper investigated the hypotheses through analyzing the sample of data. As a result, four factors affecting the success of KMS are: Awareness the role of knowledge management and the application of KMS; Motivation and commitment of employees; Culture organizations (conformity to create learning environments and encourage sharing, acquisition and use of knowledge); Stability and effectiveness of KMS. The research results agree with the results of previous researchs (Davenport et al., 1998; Alavi and Leidner, 1999; Cross and Baird, 2000; Jennex and Olfman, 2000; Barna, 2002; Yu et al., 2004).

The results of analysis showed that the influence of these 
factors that determines the success of knowledge management system has no gap; In particular, motivation and commitment of the employees have the greatest impact, the role of knowledge management and the application of KMS has a minimal impact. This confirms the human factor plays an important role for the overall knowledge management and knowledge management system (KMS). Research shows that the issues of human and organizational culture have always been respected in Vietnam enterprises.

Although KMS relates directly to information technology systems and communication (ICT), but according to the findings of non-ICT factors affecting these systems (fairly related to the stability and effectiveness of KMS and respondents mainly concentrate in two major cities which have highest levels of IT application of Vietnam).

\section{Conclusion and Implications}

In general, studies have proven models and hypotheses about factors that affect the success of knowledge management systems in businesses. Research has proven the elements related to awareness, attitude of employees, organizational culture, level of stability are factors that determine the success of KMS. From these findings, this research has following implications for academics and practitioners.

For the academics, it provided one more empirical evidences for literature. Researchers can consider and choose the direction of further research in the field of general knowledge management and knowledge management systems in particular.

For the practitioners, to ensure success for the deployment of applications of knowledge management systems, businesses need to take measures to all workers in the enterprise to understand their roles and take efforts to participate in the development and effective use of this system; Also need to create an enabling environment to encourage learning, exchanging, sharing and application of knowledge. Company should have effective investment and operation methods and efficient exploitation of knowledge management systems to support business.

Research has made contributions and discoveries, but also some limitations:

- The number of respondents was small, as knowledge management is a new field and the application of knowledge management systems is limited.

- The survey was focused mainly in two most developed cities, is not representative for the whole of Vietnam enterprises.

In the future, studies should be in a larger scale, broader scope and focus on other issues in the fields of knowledge management to help promote and improve the effectiveness of this activity in companies.

\section{References}

[1] Alavi, M., Leidner Dorothy, E. (1999). Knowledge Management Systems: Emerging Views and Practices from the Field. 32nd Hawaii International Conference on System Sciences, IEEE Computer Society.

[2] Alavi, M., Dorothy Leidner, E. (2001). "Review: Knowledge Management and Knowledge Management Systems: Conceptual Foundations and Research Issues", pg. 114.

[3] Barna, Z. (2003). Knowledge Management: A Critical EBusiness Strategic Factor. Unpublished Masters Thesis, San Diego State University.

[4] Cross, R., Baird, L. (2000). Technology Is Not Enough: Improving Performance by Building Organizational Memory. Sloan Management Review, 41(3), 41-54.

[5] Davenport, T., Prusak L. (1998). Working knowledge: How organizations manage what they know. Boston: Harvard Business School Press.

[6] Detlor, B. (2003). Internet-based information systems use in organizations: An information studies perspective. Information Systems Journal 13 (2): 113-132.

[7] Ginsberg, M., Kambil, A. (1999). Annotate: A Web-based Knowledge Management Support System for Document Collections. 32nd Hawaii International Conference on System Sciences, IEEE Computer Society Press.

[8] Holsapple, C. W., Joshi, K. D. (2000). An Investigation of Factors that Influence the Management of Knowledge in Organizations. Journal of Strategic Information Systems, 9, 235-261.

[9] Jennex, M. E., \& Olfman, L. (2004). Modeling knowledge management success. Proceedings of the Conference on Information Science and Technology Management, CISTM.

[10] Maier, R. (2002). "Knowledge Management Systems: Information And Communication Technologies for Knowledge Management (3rd edition)”. Berlin: Springer.

[11] Malhotra, Y., \& Galletta, D. (2003). Role of commitment and motivation as antecedents of knowledge management systems implementation. Proceedings of the $36^{\text {th }}$ Hawaii International Conference on System Sciences.

[12] Mandviwalla, Eulgem, Mould, Rao (1998). "Knowledge Management in Modern Organizations".

[13] Nam, T. H. (2014), The Application Knowledge Management Tools of The Enterprises in Vietnam - The Problems and Solutions, Trade Science Review, Vol. 74-75, 84-92.

[14] Rasmussen, J., Pejtersen A., and Goodstein L. (1994). Cognitive systems engineering. London: John Wiley.

[15] Sage, A. P. and Rouse, W. B. (1999). Information Systems Frontiers in Knowledge Management. Information Systems Frontiers, 1(3), 205-219.

[16] Yu, S.-H., Kim, Y.-G., \& Kim, M.-Y. (2004). Linking organizational knowledge management drivers to knowledge management performance: An exploratory study. Proceedings of the 37th Hawaii International Conference on System Sciences, HICSS36. 